\title{
MODEL PREMI TIDAK KONSTAN PADA ASURANSI DANA PENSIUN BERDASARKAN ASUMSI BESAR GAJI TERAKHIR
}

\author{
CLAUDIA PUTRI ZOELANDA, NARWEN, DODI DEVIANTO \\ Jurusan Matematika, \\ Fakultas Matematika dan Ilmu Pengetahuan Alam, Universitas Andalas, \\ Kampus UNAND Limau Manis Padang, Indonesia, \\ email : claudiaputrizoelanda@gmail.com
}

\begin{abstract}
Abstrak. Asuransi dana pensiun adalah salah satu bentuk upaya seorang pegawai untuk menjamin kesejahteraan hidup pada saat memasuki usia pensiun. Pegawai yang mengikuti asuransi pensiun harus membayarkan sejumlah uang yang disebut dengan premi yang nantinya akan diterima oleh pegawai tersebut ketika telah memasuki usia pensiun. Besarnya premi yang dibayarkan harus sesuai dengan gaji yang diterima oleh pegawai. Penelitian ini bertujuan untuk menghitung besarnya premi yang akan di bayarkan peserta agar tidak terbebani dengan pembayarannya. Dalam penelitian ini peserta mengikuti asuransi pada umur $x$ tahun dan pensiun di usia $r$ tahun. Besarnya iuran yang akan dibayarkan peserta dihitung dengan menggunakan formula premi tidak konstan dengan kenaikan tiap tahun konstan sebesar $\alpha$ dimana besar gaji tiap tahun selalu meningkat. Perhitungan dengan formula ini berdasarkan asumsi besar gaji terakhir yang diterima oleh peserta. Dengan menggunakan formula premi tidak konstan besarnya iuran yang dibayarkan oleh peserta selalu meningkat tiap tahun, tapi dengan kenaikan yang konstan sebesar $\alpha$.
\end{abstract}

Kata Kunci: Asuransi Dana Pensiun, manfaat pensiun, iuran normal, model (formula) premi tidak konstan

\section{Pendahuluan}

Dana pensiun diselenggarakan dalam upaya memberikan jaminan kesejahteraan pada karyawan yaitu salah satu bentuk upaya perencanaan masa tua dengan tujuan menjamin kesejahteraan hidup pada saat memasuki usia pensiun. Program asuransi meupakan program yang mengupayakan sejumlah pertanggungan dengan pihak-pihak yang terlibat, yaitu pihak penanggung (perusahaan asuransi) dan pihak tertanggung (peserta sebagai pemegang polis).

Pihak penanggung akan memberikan jaminan atas kerugian yang dialami tertanggung sesuai perjanjian yang disepakati kedua belah pihak. Pihak tertanggung harus membayarkan sejumlah uang yang disebut dengan premi sesuai polis yang disepakati kedua belah pihak pada awal perjanjian asuransi. Dana pensiun yang sering disebut dengan asuransi hari tua merupakan asuransi yang mengupayakan sejumlah manfaat pensiun bagi peserta pensiun yang nantinya dapat membentuk sejumlah dana untuk dipergunakan di hari tua setelah mereka tidak lagi bekerja.

Pada asuransi dana pensiun, ada beberapa kesepakatan yang harus di setujui oleh pihak tertanggung dan pihak penanggung. Kesepakatan itu adalah premi dan 
aktuaria, dimana besar premi yang akan dibayarkan oleh pihak tertanggung (pegawai) asuransi dana pensiun harus disesuaikan dengan penghasilan yang didapatkan, sehingga besar iuran premi yang akan dibayarkan tidak membebani tertanggung. Pembayaran premi akan dilakukan dalam bentuk pembayaran iuran normal dilakukan dalam bentuk pemotongan gaji pegawai. Gaji yang dipotong menjadi investasi selama masa kerja dan akumulasi dana untuk pembayaran manfaat pensiun dalam memelihara kesinambungan penghasilan peserta pada hari tua [1].

Perhitungan premi dilakukan dengan menggunakan formula perhitungan premi tidak konstan dengan kenaikan premi tiap tahunnya konstan. Formula ini menggunakan asumsi besar gaji terakhir, dan diasumsikan besar gaji selalu meningkat setiap tahunnya.

\section{Teori Asuransi}

Anuitas hidup adalah suatu rangkaian pembayaran secara kontinu atau yang dilakukan setiap interval tertentu (misalnya bulanan, empat bulanan, atau tahunan) selama pemegang polis masih hidup. Deretan pembayaran ini dapat dilakukan secara berjangka, yaitu terbatas pada jangka waktu yang diberikan atau dibayarkan seumur hidup.Anuitas hidup yang digunakan yaitu anuitas awal seumur hidup dan anuitas awal berjangka [1].

Anuitas awal seumur hidup adalah nilai tunai dari anuitas seumur hidup sebesar 1 rupiah yang dibayarkan setiap awal periode dan dimulai dari usia $x$ tahun hingga meninggal dengan bunga $i$ per periode dinotasikan dengan $\ddot{a}_{x}$ dan dirumuskan sebagai berikut

$$
\ddot{a}_{x}=\frac{N_{x}}{D_{x}}
$$

Anuitas awal berjangka adalah nilai tunai dari anuitas hidup berjangka sebesar 1 rupiah yang dibayarkan setiap awal periode dan dimulai dari usia $x$ tahun hingga meninggal selama $n$ tahun dengan bunga $i$ per periode dinotasikan dengan $\ddot{a}_{x: \bar{n}}$ dan dirumuskan sebagai berikut

$$
\ddot{a}_{x: \bar{n} \mid}=\frac{N_{x}-N_{x+n}}{D_{x}}
$$

Fungsi dasar aktuaria merupakan fungsi-fungsi yang dapat digunakan dalam perhitungan aktuaria dalam menentukan besar nilai manfaat dan iuran normal yang akan dibayarkan oleh peserta program dana pensiun. Fungsi-fungsi yang dapat digunakan adalah sebagai berikut [4] :

1. Fungsi kelangsungan hidup, merupakan fungsi yang menunjukkan kemungkinan seseorang masih akif bekerja hingga mencapai usia pensiun yang telah ditentukan. Dirumuskan dengan

$$
{ }_{t} p_{x}=\frac{l_{(x+t)}}{l_{x}}
$$

2. Fungsi tingkat suku bunga, merupakan fungsi yang digunakan untuk menghitung diskonto suatu pembayaran yang akan datang pada waktu sekarang. Misalkan $i$ merupakan tingkat suku bunga selama $t$ tahun, dimana $t=1,2, \cdots, n$ 
dan $i$ diasumsikan tidak berubah, maka diperoleh

$$
v^{n}=\frac{1}{(1+i)^{n}}
$$

3. Fungsi gaji, jika diasumsikan besarnya tingkat kenaikan gaji dengan $c$ x $100 \%$ pertahun, dan besar gaji pada seseorang yang berusia $x$ tahun adalah $S_{x}$, maka besarnya gaji yang akan diterima seseorang karyawan yang berusia $x$ tahun setelah $t$ tahun adalah

$$
S_{(x+t)}=S_{x}(1+c)^{t}
$$

4. Fungsi manfaat, digunakan untuk menghitung besarnya nilai manfaat pensiun yang akan diterima oleh karyawan pensiun dipercepat (keluar), pensiun karena tidak dapat bekerja lagi (cacat), kematian, ataupun pensiun saat mencapai usia pensiun. Manfaat yang diperoleh oleh peserta program dana pensiun merupakan proporsi gaji sebesar $k \%$ yang diakumulasi selama masa kerja berdasarkan asumsi skala gaji sebagai berikut yaitu fungsi manfaat berdasarkan asumsi gaji terakhir untuk seseorang saat usia $r$ tahun adalah $B_{r}=k(r-e) S_{(r-1)}$, fungsi manfaat berdasarkan asumsi rata-rata gaji selama $n$ tahun terakhir untuk seseorang saat usia $r$ tahun adalah $B_{r}=k(r-e) \frac{1}{n}\left[\sum_{t=r-n}^{r-1}\left(S_{x}(1+c)^{t}\right)\right]$ dan fungsi manfaat berdasarkan asumsi rata-rata gaji selama bekerja untuk seseorang saat usia $r$ tahun adalah $B_{r}=k\left[S_{e}+\cdots+S_{x}+S_{(x+1)}+\cdots+S_{(r-1)}\right]$

Pada program dana pensiun, nilai akhir pembiayaan iuran normal digunakan untuk mengetahui total pembiayaan iuran normal yang dikeluarkan peserta selama mengikuti program dana pensiun sampai memasuki usia pensiun. Jika seorang peserta masuk program dana pensiun pada usia $e$ tahun dan masih hidup saat memasuki usia pensiun (berusia $r$ tahun), maka nilai akhir total iuran normal yang dibayar peserta saat berusia $r$ tahun yang dinotasikan dengan ${ }^{r}(N A)_{e}$ adalah

$$
{ }^{r}(N A)_{e}=\sum_{x=e}^{r-1}(N C)_{x}(1+i)^{r-x}
$$

Present value of future benefit (PVFB) merupakan nilai sekarang dari manfaat pensiun yang akan diterima oleh tertanggung saat memasuki usia pensiunnya. Sistem pembayaran manfaat pensiun akan dilakukan tiap tahun sampai tertanggung meninggal, dapat dirumuskan dengan [2]:

$$
r(P V F B) x=B_{r} \ddot{a}_{r} v_{r-x}^{r-x} p_{x}
$$

Dengan $B r$ adalah besar manfaat pensiun normal yang akan diterima oleh tertanggung saat usia $r$ tahun, $\ddot{a}_{r}$ adalah anuitas awal seumur hidup di usia pensiun $r$ tahun, $v^{r-x}$ adalah faktor diskonto selama $(r-x)$ tahun dan ${ }_{r-x} P_{x}$ adalah tingkat penyusutan aktuaria total di usia $x$ tahun hingga usia $r$ tahun.

Present Value of Future Normal Cost (PVFNC) merupakan nilai sekarang dari iuran normal yang dibayarkan secara berkala oleh peserta mulai dari peserta berusia $x$ tahun sampai memasuki usia pensiun berusia $r-1$ tahun, dapat dirumuskan 
dengan [2]:

$$
r(P V F N C) x=\sum_{t=x}^{r-1}(N C)_{t} v_{L}^{t-x}{ }_{t-x} p_{x}
$$

\section{Perhitungan Iuran Normal}

Iuran normal atau normal cost $(N C)$ merupakan pembayaran rutin yang dibayarkan oleh peserta program dana pensiun kepada perusahaan program pensiun yang akhirnya dapat dialokasikan untuk memperoleh nilai manfaat yang akan diterima oleh peserta tersebut.

Iuran normal dengan metode Entry Age Normal (EAN) saat seseorang berusia $x$ tahun dan pensiun ketika usia $r$ tahun adalah

$$
E A N(N C)=\frac{B_{r} \ddot{a}_{r} v^{r-x} r-x p_{x}}{\ddot{a}_{\bar{x}: r-x}},
$$

iuran normal dengan metode Projected Unit Credit (PUC) saat seseorang berusia $x$ tahun dan pensiun ketika usia $r$ tahun adalah

$$
P U C(N C)=\frac{1}{(r-e)} B_{r} \ddot{a}_{r} v_{r-x}^{r-x} p_{x}
$$

dan iuran normal dengan model (formula) premi tidak konstan adalah konstan setiap tahunnya sebesar $\alpha$ [2]. Berikut merupakan rincian kontrak dalam program asuransi, mulai menjadi peserta program pensiun saat berusia $e$ tahun dan akan terhitung pensiun pada usia $r$ tahun.

Misalkan $P$ adalah nilai tunai yang harus dibayarkan tertanggung setiap tahunnya. Pada tahun pertama tertanggung membayarkan iuran sebesar $P$ dan tahun kedua sebesar $\alpha+P$ dan seterusnya mengalami peningkatan sebesar $\alpha$ setiap tahunnya sampai mencapai satu tahun sebelum usia pensiun. Sehingga besar iuran terakhir yang akan dibayarkan tertanggung adalah $(r-1) \alpha+P$. Sebaliknya sebagai hak yang akan didapatkan peserta pensiun bila hidup sampai usia $r-1$, akan mendapatkan tanggungan (uang pensiun) mulai usia $r$ tahun sebesar $\mathrm{Br}$ seumur hidup. Apabila peserta pensiun meninggal sebelum mencapai usia $r-1$, maka peserta pensiun tidak mendapatkan uang tanggungan apapun. Dari kontrak ini maka nilai tunai dari premi yang akan di bayarkan peserta pensiun adalah :

$$
\begin{aligned}
(P V F N C)_{e}= & \frac{1}{l_{e}}\left[P l_{e}+v(P+\alpha) l_{e+1}+v^{2}(P+2 \alpha) l_{e+2}+\cdots\right. \\
& \left.+v^{r-e-1}(P+(r-e-1) \alpha) l_{r-1}\right] \\
= & \left.\frac{1}{D_{e}}\left[P\left(N_{e}-N_{r}\right)+\alpha\left(S_{e+1}-S_{r}\right)-\alpha(r-1-e) N_{r}\right)\right]
\end{aligned}
$$

Sedangkan nilai tunai dari manfaat pensiun yang akan dibayarkan oleh perusahaan asuransi pensiun bagi peserta pensiun adalah :

$$
(P V F B)_{e}=B_{r} \ddot{a}_{r} v^{r-e}{ }_{r-e} P_{e}
$$


Berdasarkan prinsip ekuivalensi yaitu nilai sekarang dari iuran normal saat peserta berusia $x$ tahun $r(P V F N C) x$ akan sama dengan nilai sekarang manfaat pensiun saat tertanggung berusia $x$ tahun $r(P V F B) x$ maka dari persamaan (3.4) dan (3.5) diperoleh:

$$
(P V F N C)_{e}=(P V F B)_{e}
$$

sehingga,

$$
[P]=\frac{1}{(N e-N r)}\left[\left(B_{r} \ddot{a}_{r} v_{r-e}^{r-e} p_{e} D_{e}\right)-\alpha\left(S_{e+1}-S_{r}\right)+\alpha(r-1-e) N_{r}\right]
$$

dimana $[\mathrm{P}]$ menyatakan besar iuran normal pada tahun pertama, sehingga besar iuran normal pada tahun ke t adalah :

$$
[P]_{t}=P+\alpha(t-1), t=1,2,3, \cdots,(r-e)
$$

\section{Penerapan Kasus}

Misalkan seorang pegawai negeri dengan golongan II/b, berjenis kelamin laki-laki mulai menjadi pegawai pada usia 25 tahun $(e=25)$ dan mulai terhitung pensiun pada tanggal 1 Januari 2048 dengan usia 56 tahun $(r=56)$. Gaji pokok pada tahun pertama $(\mathrm{Se})$ diterima dalam setahun sebesar $R p .2 .350 .000$ dan diasumsikan meningkat $2 \%(c=2 \%)$ pertahun dari gaji pokok tahun pertama yang didapatkan dan besar nilai proporsi gaji yang diberikan untuk dana pensiun sebesar $2 \%(k=$ $2 \%$ ).

Perhitungan pembiayaan pensiun pada saat peserta diangkat menjadi pegawai $(x=25)$. Kemudian untuk tahun berikutnya iuran normal yang akan dibayarkan ditambah dengan $\alpha$ sebesar $5 \%$ dari manfaat pensiun. Dari perhitungan diperoleh:

1. Anuitas awal seumur hidup dari peserta $x=25$ tahun yaitu $\ddot{a}_{56}=16,69662$ dan anuitas awal berjangka dari peserta $x=25$ dan $n=31$ yaitu $\ddot{a}_{25: \overline{31 \mid}}=21,54869$.

2. Besar manfaat pensiun. Sebelum menghitung besarnya manfaat pensiun terlebih dahulu hitung besar gaji yang diterima setiap tahun dari mulai masuk kerja sampai mencapai usia pensiun, seperti pada Tabel 1.

Dari Tabel 1 terlihat bahwa kenaikan gaji tiap tahunnya selalu konstan dan diperoleh besar manfaat pensiun yang akan diterima peserta adalah $B_{56}=\mathrm{Rp}$. 2.639.153,82804.

3. Nilai sekarang manfaat pensiun peserta usia $x=25$ tahun sebesar 56(PVFB) 25 = Rp. 18.790.264,53945.

4. Iuran normal dengan metode entry age normal sebesar $\mathrm{EAN}(\mathrm{NC})=\mathrm{Rp}$. $871.991,03702$, iuran normal dengan metode projected unit credit sebesar $\mathrm{PUC}(\mathrm{NC})=\mathrm{Rp} .606 .137,56579$ dan iuran normal dengan model(formula)premi tidak konstan sebesar $[\mathrm{P}]=$ Rp. 309.949,76058.

Terlihat dari Gambar 1 untuk grafik berwarna biru adalah peningkatan besar iuran normal tiap tahun dengan metode entry age normal dan grafik berwarna merah adalah peningkatan besar iuran normal tiap tahun dengan metode projected unit credit sedangkan grafik berwarna abu-abu adalah peningkatan besar iuran normal tiap tahun dengan model premi tidak konstan. 
Tabel 1. Tabel Besar Gaji Peserta Program Dana Pensiun

\begin{tabular}{|c|c||c|c||c|c|}
\hline $\mathrm{n}$ & $\mathrm{S}(\mathrm{x}+\mathrm{n})$ & $\mathrm{n}$ & $\mathrm{S}(\mathrm{x}+\mathrm{n})$ & $\mathrm{n}$ & $\mathrm{S}(\mathrm{x}+\mathrm{n})$ \\
\hline \hline 0 & 2.350 .000 & 11 & $2.921 .929,62473$ & 22 & $3.633 .052,22632$ \\
\hline 1 & 2.397 .000 & 12 & $2.980 .368,21722$ & 23 & $3.705 .713,27085$ \\
\hline 2 & 2.444 .940 & 13 & $3.039 .975,58157$ & 24 & $3.779 .827,53627$ \\
\hline 3 & $2.493 .838,8$ & 14 & $3.100 .775,58157$ & 25 & $3.855 .424,08699$ \\
\hline 4 & $2.543 .715,576$ & 15 & 3.162 .790 & 26 & $3.932 .532,56873$ \\
\hline 5 & $2.594 .589,88752$ & 16 & 3.226 .046 & 27 & $4.011 .183,22011$ \\
\hline 6 & $2.646 .481,68527$ & 17 & 3.290 .567 & 28 & $4.091 .406,88451$ \\
\hline 7 & $2.699 .411,31898$ & 18 & 3.356 .378 & 29 & $4.173 .235,02220$ \\
\hline 8 & $2.753 .399,54536$ & 19 & $3.423 .506,25544$ & 30 & $4.256 .699,72264$ \\
\hline 9 & $2.808 .467,53626$ & 20 & $3.491 .976,38055$ & 31 & $4.341 .833,71710$ \\
\hline 10 & $2.864 .636,88699$ & 21 & $3.561 .815,90816$ & & \\
\hline
\end{tabular}

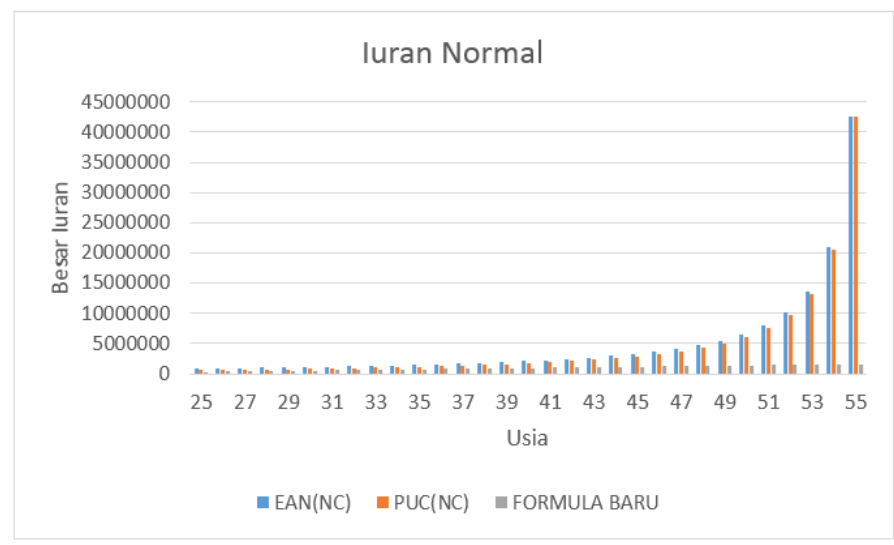

Gambar 1. Grafik Perbandingan 3 Iuran Normal

Dengan menggunakan metode entry age normal dan metode projected unit credit besar iuran normal yang akan di bayarkan oleh peserta selalu meningkat, namun peningkatan tiap tahun nya tidak konstan. Terlihat dari grafik, ketika umur 55 tahun besar iuran normal yang harus dibayarkan peserta melonjak naik.

Sedangkan dengan model premi tidak konstan besar iuran yang akan di bayarkan peserta meningkat sebesar $\alpha$ setiap tahunnya. Sehingga untuk peserta asuransi sebaiknya memilih model premi tidak konstan agar pembayaran iuran normal yang dilakukannya tidak membebaninya karena kenaikan tiap tahun selalu konstan.

5. Nilai akhir dengan metode entry age normal sebesar $\mathrm{EAN}(\mathrm{NA})=$ Rp. 187.210.448,59449, nilai akhir dengan metode projected unit credit sebesar $\mathrm{PUC}(\mathrm{NA})=$ Rp. 170.591.044,98768 dan nilai akhir dengan model(formula) 
premi tidak konstan sebesar $[\mathrm{P}](\mathrm{NA})=\mathrm{Rp} .41 .428 .425,58759$.

\section{Kesimpulan}

Berdasarkan penelitian yang telah dilakukan, diperoleh bahwa

1. Model (formula) premi tidak konstan dengan kenaikan konstan setiap tahunnya berdasarkan asumsi besar gaji terakhir adalah sebagai berikut :

$$
[P]=\frac{1}{(N e-N r)}\left[\left(B_{r} \ddot{a}_{r} v_{r-e}^{r-e} P_{e} D_{e}\right)-\alpha\left(S_{e+1}-S_{r}\right)+\alpha(r-1-e) N_{r}\right]
$$

dimana $\mathrm{P}$ merupakan besar iuran normal yang akan dibayarkan peserta program dana pensiun pada tahun pertama. Untuk pembayaran iuran normal pada tahun ke-t digunakan model (formula) sebagai berikut :

$$
[P]_{t}=P+\alpha(t-1), t=1,2,3, \cdots,(r-e)
$$

2. Berdasarkan penerapan kasus, terlihat bahwa dengan menggunakan model (formula) premi tidak konstan, pembayaran iuran normal setiap tahunnya jauh lebih kecil dibandingkan dengan menggunakan metode entry age normal dan metode projected unit credit. Dimana $\mathrm{P}$ (formula baru $)<\mathrm{P}(\mathrm{PUC})<\mathrm{P}(\mathrm{EAN})$. Oleh karena itu, perhitungan pembiayaan iuran normal dari sudut pandang peserta program dana pensiun dapat memilih perhitungan dengan menggunakan model (formula) premi tidak konstan dengan kenaikan konstan. Sehingga peserta program dana pensiun tidak merasa terbebani dengan kenaikan iuran normal setiap tahunnya karena kenaikan yang tejadi selalu konstan setiap tahunnya.

\section{Daftar Pustaka}

[1] Futami, T. 1993. Matematika Asuransi Jiwa Bagian I. Herliyanto, Gatot, penerjemah.Tokyo: Oriental Life Insurance Cultural Development Center. Terjemahan dari : Seimei Hoken Sugaku, Jokan

[2] Futami, T. 1993. Matematika Asuransi Jiwa Bagian II. Herliyanto, Gatot, penerjemah.Tokyo: Oriental Life Insurance Cultural Development Center. Terjemahan dari : Seimei Hoken Sugaku, Jokan

[3] Larson,R.E.,E.A. Gaumnitz.1962. Life Insurance Mahematics.John Wiley dan Sons,Inc.New York.

[4] Winklevoss, H.E. 1993. Pension Mathematics with Numerical Illustrations, $2^{\text {nd }}$ edition. Pension Research Council, USA. 